\title{
Recognition of earthquake-prone areas in the Altai-Sayan-Baikal region based on the morphostructural zoning
}

\author{
A. I. Gorshkov ${ }^{1}$ and A. A. Soloviev ${ }^{1}$ \\ Received 20 September 2020; accepted 21 November 2020; published 3 February 2021.
}

The goal of the study is to identify the possible locations of strong M6+ earthquakes in the Altai-Sayan-Baikal region. The first stage of the study is compiling the morphostructural map of the region by means of the morphostructural zoning method (MSZ). The map presents the hierarchical block structure of the region, the network of morphostructural lineaments bounding the blocks, and loci of the nodes forming around lineament intersections. Epicenters of M6+ earthquakes reported by earthquake catalogues nucleate at nodes. We apply the pattern recognition approach to identify among all nodes seismogenic nodes $\mathbf{D}$ capable of generating $\mathrm{M} 6+$ earthquakes. This is done based on the description of the nodes by a set of geological and geophysical characteristics measured uniformly for all nodes. The result of the pattern recognition is twofold: (i) the rule of recognition that allows to recognize $\mathbf{D}$ nodes among the whole set of nodes; (ii) the actual division of nodes according to this rule into separate two classes: seismogenic $\mathbf{D}$ nodes and $\mathbf{N}$ nodes where the target events are unlikely. In the region under consideration, the whole set of 97 nodes has been divided into 33 $\mathbf{D}$ nodes and $64 \mathbf{N}$ nodes. The target earthquakes have not yet been recorded at $17 \mathbf{D}$ nodes indentified in this work. These susceptible nodes are located on the high rank lineaments separating major morphostructures of the region. High seismic potential of some of such nodes is confirmed by paleoseismic features defined in the region by other researchers. KEYWORDS: Altai-Sayan-Baikal region; morphostructural zoning; pattern recognition; seismogenic nodes.

Citation: Gorshkov, A. I. and A. A. Soloviev (2021), Recognition of earthquake-prone areas in the Altai-Sayan-Baikal region based on the morphostructural zoning, Russ. J. Earth. Sci., 21, ES1005, doi:10.2205/2020ES000751.

\section{Introduction}

For an adequate assessment of seismic hazard, it is necessary to know the areas where strong earthquakes are possible. Information on the strong earthquakes recorded in the region under consideration is insufficient to identify such areas, since instrumental seismological observations were begun only a little earlier than 100 years ago, and it is

\footnotetext{
${ }^{1}$ Institute of Earthquake Prediction Theory and Mathematical Geophysics, Moscow, Russia

Copyright 2021 by the Geophysical Center RAS. http://rjes.wdcb.ru/doi/2020ES000751-res.html
}

reasonable to assume that not all potentially hazardous areas had strong earthquakes during this interval. Therefore, the problem arises of determining in the region the entire set of areas where strong earthquakes are possible. One of the approaches to solving this problem was formulated in the early 1970s by Gelfand et al., 1972 and was further developed in a series of studies Gvishiani et al., 2020.

The initial idea of this approach is that the epicenters of sufficiently strong earthquakes (with magnitudes $M \geq M_{0}$, where $M_{0}$ is a certain threshold) are confined to the intersections of morphostructural lineaments, called morphostructural nodes [Gelfand at al., 1972]. The morphostructural linea- 
ments are delineating in the region with the morphostructural zoning (MSZ) method. The morphostructural map showing the results of the MSZ analysis presents the hierarchical block structure of the region, the network of morphostructural lineaments bounding blocks, and loci of the nodes. The MSZ approach was developed by Rantsman, 1979 and its description can be found in Alekseevskaya et al., 1977. Gorshkov et al., 2003a, Rantsman, 1979, and Gorshkov, 2010. Gvishiani and Soloviev, [1981 proposed a statistical method that analyzes the mutual spatial distribution of epicenters and intersections of morphostructural lineaments to test the confinement of epicenters to intersections. Application of this method to the region studied in this work confirms the confinement. Thus, the problem of determining areas where strong earthquakes are possible can be solved by identifying among all nodes resulted from MSZ seismogenic D nodes at which the target earthquakes are likely to occur.

The pattern recognition approach is used to determine seismogenic nodes. All nodes are considered as recognition objects, and each of them is described by a vector of geological and geophysical characteristics measured for the corresponding nodes. The nodes hosting the epicenters of observed strong earthquakes form a training set for the pattern recognition algorithm. As a result of the algorithm application, the conditions for the values of the characteristics (recognition rule) are formulated, which allow us to classify the vectors corresponding to nodes and classification is obtained in accordance with this rule of all nodes into two classes: seismogenic nodes $\mathbf{D}$ where the target events may occur and nodes $\mathbf{N}$, at which only the earthquakes of $M<M_{0}$ are possible.

The approach described above was successfully applied to determine the strong earthquake-prone areas in many seismically active regions [e.g., Bhatia et al., 1992, Caputo etal., 1980, Chunga et al., 2010. Cisternas et al., 1985, Gelfand et al., 1972, 1976. Gorshkov et al., 2000, 2002, 2003b, 2004, 2009a, 2009b, 2010, 2012, 2017, 2019, 2020, Gorshkov and Gaudemer, 2019, Gvishiani and Soloviev, 1984; Gvishiani et al., 1987, 1988, Kossobokov, 1983. Novikova and Gorshkov, 2013, 2016, 2018. Soloviev et al., 2013, 2016. The locations of the earthquake epicenters that occurred in these regions after obtaining the corresponding results provide arguments in favor of the fact that these re- sults are reliable: about $87 \%$ of these epicenters fall in the recognized earthquake-prone areas [Gorshkov and Novikova, 2018, Soloviev et al., 2014.

The Altai-Sayan-Baikal region is considered in this work. It is a region of moderate seismicity, and "strong" earthquakes we determined by the magnitude threshold $M_{0}=6.0$. Recognition objects, morphostructural nodes, were defined exploiting the MSZ method [Alekseevskaya et al. 1977; Gorshkov et al., 2003a. Gorshkov, 2010, Rantsman 1979. Recognition objects are described by a set geological and geophysical characteristics that were previously used in similar studies [e.g., Soloviev et al., 2016. We use the CORA-3 pattern recognition algorithm [Gelfand et al., 1976], which was previously successfully applied to solve the same problem for many other seismic regions. As Peresan et al. 2011, 2015 demonstrated, the results of strong earthquake-prone areas identification are very helpful in assessing seismic hazard.

\section{Morphostructural Zoning of the Altai-Sayan-Baikal Region}

The considered part of the of South Siberia mountains encompasses the mountain systems of the Altai, Western and Eastern Sayan, and the Baikal rift depression. The formation of the Cenozoic structure of this region developed under the influence of the Indo-Eurasian collision, accompanied by the transfer of deformations over long distances through the rigid structures of the Precambrian microcontinent located among the Paleozoic-Mesozoic folded zones [Dobretsov et al., 1995, 2016, Buslov et al., 2008, 2013. The tectonic structures of Altai and Sayan were formed as a result of the Hercynian and Caledonian folding, and the formation of the recent relief took place in the Late Cenozoic in the Oligocene-Quaternary time during 5-3 million years [Buslov et al., 2008, Dergunov, 1989]. In the tectonic structure of the region, an important role is played by the Paleozoic and Mesozoic faults, renewed in the Cenozoic time [Dergunov, 1989, Dobretsov et al., 1995, 2016. These faults determine the block structure of the basement, which is clearly expressed in the morphostructure of the study region [Novikov, 2004]. The study of active faults has shown their kinematic diversity and wide distribution in the region [Imaev et al., 2006, Lukina, 
1996. Sherman et al., 2015. Trifonov et al., 2002. The current regional geodynamics and seismicity is determined by regional compression created by the ongoing interaction of the Eurasian and Indian plates [Molnar and Tapponnier, 1975].

MSZ was exploited in this work for identifying objects of recognition. The method was developed by Rantsman, 1979 and in every detail is presented in [Gorshkov et al., 2003a; Gvishiani et al., 1988. Rantsman, 1979. Here, we introduce the basic definitions of MSZ, the goal of which is delineating the hierarchical lineament-and-block structure of the region. Three hierarchical levels of morphologically homogeneous blocks and lineaments bounding blocks are distinguished in MSZ. Morphostructural nodes are formed around of intersections of lineaments. The blocks are characterized by similar values of the quantitative relief indicators (level of heights, orientation of linear relief forms). Block boundaries are associated with sites where the value of at least one indicator changes sharply and significantly. Blocks and their boundaries are assigned the third, lowest rank in the hierarchy. Blocks are integrated into megablocks if the quantitative relief indicators from one block to another change sequentially. Megablock boundaries are established at sites where the sequence breaks down. Megablocks and their boundaries are assigned the second rank. In MSZ, the first rank unit is a mountain country - a territory of a single relief appearance (e.g. mountains or plain) and one type of orogeny.

Two types of morphostructural lineaments are distinguished: longitudinal and transverse. The longitudinal lineaments are nearly parallel to the axes and foothills of the ridges, the strike of the longitudinal valleys and intermontane basins; they usually include prominent fault zones. Transverse lineaments cross large relief elements obliquely or at right angles. They are traced at sites where the values of quantitative relief indicators sharply and significantly change. Zones of transverse lineaments include sections of rectilinear river valleys, faults elongated in a single direction, and tectonic scarps.

Topographic and geological maps at scales 1:500,000-1:1,000,000, as well as satellite images and literature data, formed the set of the initial data for compiling the MSZ map.

According to the MSZ principles [Alekseevskaya et al., 1977, Gorshkov et al., 2003, five territorial units of the highest (first rank) were identified in the studied region (Figure 1). These are Gorny
Altai, Western Sayan, Eastern Sayan, Tuva Mountains, and the depression of Lake Baikal.

Gorny Altai. Within the study region, we consider Gorny Altai - the northern (Russian) part of Altai. The mountain country is represented by a system of ridges converging in the south and fanshaped in the north. In the south, the number of ridges is $4-5$, while in the north it increases to 8 or more. In the north, the ridges rise above the plains adjacent to Altai by about $1000 \mathrm{~m}$, and in the south up to $2000-2500 \mathrm{~m}$. The ridges are separated by wide rectilinear valleys and a large number of elongated depressions, which distinguishes Altai from the neighboring mountain country of the Western Sayan.

Lineaments of the first rank separate the Altai mountain country from the adjacent large-scale structures: Kuznetsk Alatau in the north, Rudny Altai in the west, Western Sayan in the east. In the south, a near-latitudinal lineament $11-17$ of the second rank separates the northern Altai from the more elevated ridges of the Mongolian Altai. Lineament zone 11-17 is traced along the system of latitudinal sections of river valleys and corresponds to a large tectonic fault. Lineament 1-11, traced along the valley of the Charysh River, separates Gorny and Rudny Altai. The lineament is consistent with the Charysh fault. The transverse lineament 17-22 separates Altai from the Western Sayan and runs from the basin of Lake Teletskoye in south-east direction along the valley of the river Kobda and small depressions lying in the southeastern strike, up to the basin of the Lake Achit-Nur. The lineament zone includes the Teletsky and Kuraisky faults.

The mountain country of Altai is divided into four megablocks from A-I to A-IV in Figure 1. They differ in the level of heights and dominate strike. The mountain ranges in megablocks A-I and A-II are significantly lower than the ridges that make up megablocks A-III and A-IV. The boundaries of megablocks are lineaments of the second rank. Lineament $2-14-18$ separates the high ridges of the southern Altai from the lower ridges of the northern Altai. Lineament of the second rank 513 is traced along the Katun River valley and separates megablocks with different dominant strike of ridges. Longitudinal lineaments of the third rank are oriented in the NW direction and separate ridges of different height. The transverse lin- 


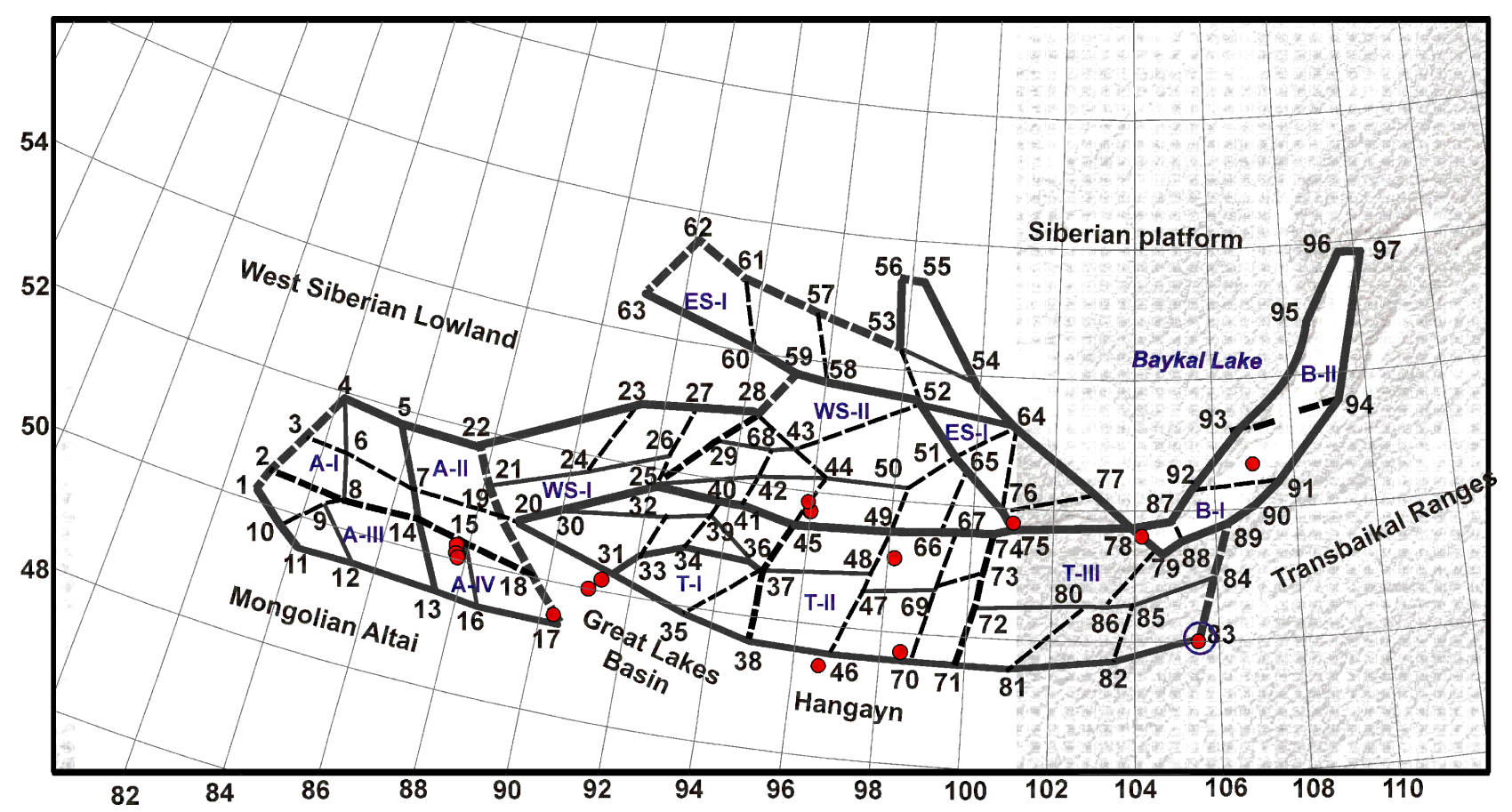

Figure 1. Morphostructural map of the Altai-Sayan-Baikal region. Continuous lines mark the longitudinal lineaments, dashed lines depict the transverse lineaments. Bold lines show the lineaments of the 1st rank, middle lines mark the lineaments of the 2nd rank, hairlines depict the lineaments of the 3rd rank. Red dots depict epicentres of earthquakes M6+. A - Altai, WS - Western Sayan, EW - Eastern Sayan, B - Baikal, T

- Tuva Mountains. Roman figures indicate numbers of nodes.

eaments have a near E-W orientation and control local changes in the height and strike of the Altai ridges.

Western Sayan. The Western Sayan Mountains are represented by a mountain range stretching in the near W-E direction for $550 \mathrm{~km}$ with a width of about $150 \mathrm{~km}$. The dividing ridge of the Western Sayan Mountains in the western part has a height of 2800-3000 $\mathrm{m}$. To the east of the valley of the river Yenisei the relief acquires a mid-mountain character, dropping to almost $2000 \mathrm{~m}$. In the north, the Western Sayan joins rather steeply the Minusinsk Basin, in the south it relatively smoothly passes into the Usinskaya and Turano-Uyukskaya depressions developed on the southern slope of the Western Sayan. In the north, the lineament 22-59 of the first rank separates the Western Sayan from the Kuznetsk Alatau ranges and Kuznetsk depression developed within the Siberian plate, and corresponds to the North Sayan fault. In the south, an extended first rank lineament 20-75 separates the Western Sayan from the Tuva Mountains and from the Fore-Baikal ridges; it consistent with the
Okinsko-Zhomboloksky and Tunkinsky faults. First rank lineaments 52-59 and 52-75 separate the Western and Eastern Sayan. The transverse lineament 25-28 of the second rank divides the Western Sayan into two megablocks WS-I and WS-II. The height of the ridges in the megablock WS-I is $2800-3000 \mathrm{~m}$, while in the WS-II megablock it sharply decreases to $2000 \mathrm{~m}$. Unlike megablock WS-I, large intramontane basins are widely developed in the megablock WS-II.

Eastern Sayan. In contrast to the near E-W strike of the Western Sayan, the watershed ridge of the Eastern Sayan is oriented in the north-western direction. In the northeast and east of the Eastern Sayan, the first rank lineaments 53-62 and 5578 separate the mountain structure from the plains of the Siberian platform. Lineament 55-78 corresponds to the East Sayan deep-seated fault. The transverse lineament 52-64 divides the mountain country into two megablocks ES-I and ES-II Figure 1) differing in height and strike of the axial ridges 
Tuva Mountains. This mountain country includes the Tannuol Ranges system and the Forebaikal ranges in its eastern part. From the south, this area is limited by a longitudinal lineament of the second rank 20-83 corresponding to the Khangai fault zone. In the east, the boundary of the mountain country is a transverse lineament of the first rank 83-89, which runs just east of the valley of the Selenga River and separates the different systems of the Forebaikal and Transbaikal ridges. Three megablocks have been delineated within the Tuva Mountains. Megablock T-I includes the basin of Lake Uus Nuur. The lineaments bounding the basin are consistent with active faults defined in the region [Sherman et al., 2015]. Megablok T-II includes the Western and Eastern Tannuol Ranges. Megablock T-III is represented by mountain ranges separated by large depressions. The eastern boundary of the megablock is a second rank transverse lineament 71-74, traced along Lake Hovsgol and corresponding to a large active fault [Sherman et al., 2015.

Baikal. This is the first rank unit presented by the deep-water basin of the Lake Baikal. The depression is bounded by the first rank lineaments 87-95 in the west and 79-94 in the east. The Baikal depression is divided into two megablocks. The deeper-water part includes megablock B-I. In megablock B-II, the depth of the depression decreases and its strike changes from northeastern to near N-S. The megablock boundary, transverse lineament 93-94, follows along Olkhon Island, the strike of which is controlled by an active fault [Lunina et al., 2012.

The third rank lineaments form the boundaries of the blocks. They control changes in elevation and strike of ridges within megablocks. Lineaments are traced along rectilinear lengths of river valleys and usually correspond to fault zones.

Each intersection of morphostructural lineaments shown in Figure 1 we treat as a node. As it was demonstrated in some previously studied regions [Gorshkov et al., 2009b] Gvishiani et al., 1988, Rantsman, 1979, node is an area of some extent, the natural boundaries of which can be mapped during the time consuming field works. When field works were not performed, we threat as a node the circle of a certain radius centered at the point of lineament intersection. The radius depends on the target magnitude. In this work, we consider circles of $25 \mathrm{~km}$ in radius. This is consistent with the size of earthquake source of M6 earthquakes [Wells and Coppersmith, 1994.

Figure 1 shows that earthquakes reported by earthquake catalogues [Kondorskaya and Shebalin, 1977, Kondorskaya et al., 1982, 1993 , the catalog of the U.S. National Earthquake Information Center (NEIC)| correlate with nodes.

\section{Objects of Recognition and Characteristics Describing Them}

Objects of recognition are associated with the morphostructural nodes. The number of nodes is 97. Each of them is described by a vector with components that are values of characteristics measured uniformly for all nodes under consideration. Our problem is to separate the vectors (and the respective nodes) into classes $\mathbf{D}$ and $\mathbf{N}$.

The following characteristics measured in circles of $25 \mathrm{~km}$ radius with centers in relevant intersections are used in this study.

Topographic characteristics: the maximal $\left(H_{\max }\right)$ and minimal $\left(H_{\min }\right)$ altitudes in the circle, $\Delta H=$ $H_{\max }-H_{\min }, l$ - distance between points where $H_{\max }$ and $H_{\min }$ are measured, and $\mathrm{g} H=\Delta H / l$.

Geological characteristic $(Q)$ : the portion (in \%) of the circle area covered by soft (quaternary) sediments.

Morphological characteristic (Mor) that reflects the main landform combination in the circle and takes on the following four values: 1 - mountains/plains; 2 - mountains/piedmont; 3 - mountains/mountains; 4 - piedmont/plains.

Characteristics reflecting the geometry of the lineament-block structure: the number $\left(N_{l}\right)$ and the highest rank $\left(R_{h}\right)$ of the lineaments forming the node; distances from the nodes to the nearest other node $\left(D_{\text {int }}\right)$, to the nearest first rank $\left(D_{1}\right)$ and second rank $\left(D_{2}\right)$ lineament, and the number of lineaments in the circle $\left(N_{l c}\right)$.

Gravitational characteristics: the maximal $\left(B_{\max }\right)$ and minimal $\left(B_{\min }\right)$ Bouguer anomalies in the circle, and $\Delta B=B_{\max }-B_{\min }$.

Geomagnetic characteristics: the maximal $\left(A_{\max }\right)$ and minimal $\left(A_{\max }\right)$ magnetic anomalies in the circle, and $\Delta A=A_{\max }-A_{\min }$. The source of the data 
on the magnetic field anomalies is the digital map that was recently prepared under the World Digital Magnetic Anomaly Map (WDMAM) international scientific project [Dyment et al., 2015]. The WDMAM map is represented in the form of the grid data with the resolution of 3 arc min over the entire surface of the Earth, which determine the intensity of the magnetic anomalies at a height of $5 \mathrm{~km}$ above the new World Geodetic System (WGS84) ellipsoid for the continental part and at sea level for the oceanic regions. The values of the anomalies are the total intensities of the field minus the main magnetic field model CM4 for 1990 [Sabaka et al., 2004.

After measurement of these 19 characteristics for all nodes the respective vectors with 19 components are treated as objects of recognition.

\section{Selection of Training Sets}

Application of the CORA-3 algorithm requires a training set of objects (vectors), for which we assume a priori the class ( $\mathbf{D}$ or $\mathbf{N})$ they belong to. This training set consisting of two subsets $\mathbf{D}_{0}$ and $\mathbf{N}_{0}$ is formed on the basis of the data on seismicity observed in the region. In the case of the AltaiSayan-Baikal region the training objects of class $\mathbf{D}$ (the subset $\mathbf{D}_{0}$ ) are all nodes that host epicenters of reported shallow earthquakes with $M \geq 6.0$ within a $50 \mathrm{~km}$ radius. The training objects of class $\mathbf{N}$ (the subset $\mathbf{N}_{0}$ ) are all nodes that do not contain epicenters of reported shallow earthquakes with $M \geq 5.0$ within a $50 \mathrm{~km}$ radius.

The catalog of earthquakes with $M \geq 5.0$ used for forming the training sets is given in Table 1 . It was compiled on the basis of the regional earthquake catalogs [Kondorskaya and Shebalin, 1977. Kondorskaya et al., 1982, 1993 and the data provided by the U.S. National Earthquake Information Center (NEIC) for the period of 1900-2013.

As a result the subset $\mathbf{D}_{0}$ consisted of 16 objects (15, 17, 31, 44-46, 48, 49, 70, 74-76, 78, 79, 83, 91 ) and the subset $\mathbf{N}_{0}$ consisted of 51 objects (112, 21-24, 27-30, 35-37, 40-42, 51-56, 58-64, 69, $71-73,80-82,84-86,93,95)$. The rest of 30 objects (the set $\mathbf{X}$ ) are not included in the training set and classified only. It is necessary to emphasize that $\mathbf{N}_{0}$ is not "pure" training set in the sense that some of its members may belong to class $\mathbf{D}$, i.e. earthquakes with $M \geq 6.0$ can occur near of some of these objects but are not known, as the interval of observations is short. Such a fussy type of learning highlights a specific difficulty in locating possible earthquake-prone areas by pattern recognition techniques.

\section{Discretization of Characteristics and Their Informativity}

The CORA-3 algorithm, which is used to investigate the problem, works in a binary vectors space. Therefore, prior to applying the algorithm the objects of recognition that are vectors with real components (values of the characteristics) should be converted in vectors with binary components. For this purpose, the characteristics are discretized, i.e. ranges of their values are represented as the union of disjoint parts. Usually the number of the parts is 2 or 3 . Then for each characteristic its values are substituted by values of components of a binary vector that indicate the part which contains the characteristic value. This procedure is described in details, e.g., in [Gelfand et al., 1976] Gorshkov et al., 2003a; Gorshkov, 2010, Gvishiani et al., 1988. After discretization the data become robust. If a range of a characteristic is divided into two parts, then only two gradations ("small" and "large") are used after the discretization instead of the exact characteristic's value. If the range is divided into three parts then the number of gradations is 3 : "small", "medium", and "large". The discretization causes the loss of information but makes results of recognition stable to variations of data.

If the discretization is made for a characteristic then the characteristic informativity can be preliminarily estimated. This is done as follows. For all discretization parts we calculate $P_{i}^{D}$ - the percentage of the objects of the training set $\mathbf{D}_{0}$ which have the corresponding characteristic values falling into part number $i$. Similar percentages $P_{i}^{N}$ are calculated for the training set $\mathbf{N}_{0}$. The value of

$$
P=\max _{i}\left|P_{i}^{D}-P_{i}^{N}\right|
$$

is regarded as a measure of the characteristic informativity for separating the recognition objects into classes $\mathbf{D}$ and $\mathbf{N}$.

For the characteristic two and three discretization parts have been considered. The discretiza- 
Table 1. Earthquakes with $M \geq 5.0$ Occurred in the Altai-Sayan-Baikal Region, 1900-2018

\begin{tabular}{|c|c|c|c|c|c|c|c|}
\hline \multirow[t]{2}{*}{ Date } & \multicolumn{2}{|c|}{ Epicenter coordinates } & \multirow[t]{2}{*}{ Magnitude } & \multirow[t]{2}{*}{ Date } & \multicolumn{2}{|c|}{ Epicenter coordinates } & \multirow[t]{2}{*}{ Magnitude } \\
\hline & Latitude & Longitude & & & Latitude & Longitude & \\
\hline 02.12 .2013 & 53.42 & 91.76 & 5.00 & 21.03 .1999 & 55.94 & 110.27 & 5.90 \\
\hline 03.04 .2013 & 51.25 & 92.40 & 5.30 & 21.03 .1999 & 55.90 & 110.21 & 5.90 \\
\hline 02.01 .2013 & 49.80 & 87.64 & 5.30 & 26.02 .1999 & 51.66 & 104.94 & 5.00 \\
\hline 06.06 .2012 & 51.71 & 96.04 & 5.10 & 25.02 .1999 & 51.63 & 104.74 & 5.10 \\
\hline 26.02 .2012 & 51.69 & 95.98 & 5.20 & 25.02 .1999 & 51.60 & 104.86 & 5.90 \\
\hline 26.02 .2012 & 51.69 & 96.08 & 5.10 & 21.11 .1998 & 49.23 & 89.19 & 5.20 \\
\hline 26.02 .2012 & 51.71 & 95.99 & 6.70 & 29.06 .1995 & 51.96 & 103.10 & 5.80 \\
\hline 27.12 .2011 & 51.84 & 95.91 & 6.60 & 22.06 .1995 & 50.37 & 89.95 & 5.50 \\
\hline 16.07 .2011 & 52.88 & 108.44 & 5.30 & 31.08 .1994 & 49.48 & 94.21 & 5.00 \\
\hline 10.02 .2011 & 52.13 & 91.78 & 5.30 & 13.03 .1994 & 50.92 & 92.17 & 5.00 \\
\hline 06.03 .2010 & 48.90 & 91.48 & 5.10 & 14.02 .1992 & 53.90 & 108.87 & 5.40 \\
\hline 04.08 .2009 & 50.65 & 96.87 & 5.30 & 28.12 .1991 & 51.10 & 98.06 & 5.00 \\
\hline 27.08 .2008 & 51.61 & 104.16 & 6.30 & 27.12 .1991 & 51.12 & 98.15 & 6.40 \\
\hline 16.08 .2008 & 52.24 & 98.29 & 5.00 & 27.05 .1991 & 49.52 & 94.76 & 5.10 \\
\hline 16.08 .2008 & 52.27 & 98.21 & 5.70 & 15.11 .1990 & 51.12 & 93.24 & 5.00 \\
\hline 20.05 .2008 & 53.30 & 108.43 & 5.30 & 13.05 .1989 & 50.10 & 105.36 & 5.70 \\
\hline 19.01 .2008 & 51.38 & 98.05 & 5.10 & 23.07 .1988 & 48.71 & 90.57 & 5.90 \\
\hline 31.10 .2007 & 49.85 & 91.68 & 5.10 & 30.06 .1988 & 50.23 & 91.14 & 5.30 \\
\hline 04.07 .2007 & 55.47 & 110.30 & 5.40 & 11.05 .1987 & 51.71 & 105.48 & 5.00 \\
\hline 11.12 .2006 & 55.76 & 110.05 & 5.10 & 04.11 .1986 & 50.88 & 89.27 & 5.60 \\
\hline 04.12 .2006 & 55.77 & 110.08 & 5.20 & 20.01 .1984 & 50.61 & 96.46 & 5.20 \\
\hline 27.04 .2005 & 51.10 & 98.31 & 5.30 & 03.08 .1982 & 48.93 & 89.70 & 5.40 \\
\hline 24.01 .2004 & 50.20 & 87.30 & 5.00 & 14.01 .1982 & 54.84 & 110.28 & 5.10 \\
\hline 17.11 .2003 & 50.19 & 87.65 & 5.20 & 16.08 .1981 & 50.63 & 96.86 & 5.10 \\
\hline 11.11 .2003 & 50.15 & 87.89 & 5.10 & 27.05 .1981 & 54.01 & 108.79 & 5.10 \\
\hline 23.10 .2003 & 49.93 & 88.34 & 5.10 & 22.05 .1981 & 52.00 & 105.76 & 5.10 \\
\hline 17.10 .2003 & 50.17 & 87.75 & 5.20 & 03.08 .1978 & 52.14 & 96.89 & 5.50 \\
\hline 13.10 .2003 & 50.26 & 87.70 & 5.20 & 01.04 .1976 & 51.12 & 97.96 & 5.20 \\
\hline 09.10 .2003 & 50.09 & 87.86 & 5.00 & 29.11 .1974 & 51.75 & 98.94 & 5.20 \\
\hline 01.10 .2003 & 50.10 & 87.63 & 5.00 & 22.03 .1974 & 49.90 & 90.81 & 5.50 \\
\hline 01.10 .2003 & 50.02 & 87.82 & 5.00 & 31.08 .1972 & 52.35 & 95.48 & 5.50 \\
\hline 01.10 .2003 & 50.21 & 87.72 & 6.70 & 26.02 .1972 & 50.46 & 97.21 & 5.70 \\
\hline 29.09 .2003 & 50.00 & 87.89 & 5.10 & 24.08 .1971 & 52.20 & 91.47 & 5.80 \\
\hline 27.09 .2003 & 50.02 & 87.86 & 5.30 & 15.05 .1970 & 50.18 & 91.27 & 6.30 \\
\hline 27.09 .2003 & 50.09 & 87.76 & 6.40 & 13.08 .1962 & 53.62 & 108.66 & 5.60 \\
\hline 27.09 .2003 & 50.07 & 87.83 & 5.00 & 20.11 .1961 & 50.90 & 92.54 & 5.60 \\
\hline 27.09 .2003 & 49.99 & 87.84 & 5.10 & 06.10 .1960 & 52.87 & 107.93 & 5.70 \\
\hline 27.09 .2003 & 50.07 & 87.94 & 5.40 & 30.08 .1959 & 52.76 & 107.15 & 5.40 \\
\hline 27.09 .2003 & 49.94 & 88.03 & 5.30 & 29.08 .1959 & 52.68 & 106.98 & 6.10 \\
\hline 27.09 .2003 & 50.04 & 87.81 & 7.30 & 23.06 .1958 & 52.07 & 99.78 & 5.70 \\
\hline 10.10 .2001 & 52.49 & 106.72 & 5.20 & 06.02 .1957 & 50.00 & 105.50 & 6.30 \\
\hline 27.10 .2000 & 54.71 & 94.98 & 5.50 & 06.09 .1953 & 50.49 & 90.07 & 5.70 \\
\hline 31.05 .2000 & 51.69 & 104.94 & 5.00 & 04.04 .1950 & 51.77 & 101.00 & 6.90 \\
\hline 21.12 .1999 & 55.83 & 110.03 & 5.50 & 19.10 .1938 & 49.50 & 90.30 & 7.10 \\
\hline 31.05 .1999 & 55.80 & 110.17 & 5.00 & 25.08 .1922 & 50.00 & 91.00 & 6.60 \\
\hline 30.05 .1999 & 55.80 & 110.03 & 5.20 & 23.07 .1905 & 49.30 & 96.20 & 8.20 \\
\hline 27.05 .1999 & 55.81 & 110.04 & 5.10 & 09.07 .1905 & 49.50 & 97.30 & 7.60 \\
\hline
\end{tabular}


tion thresholds are computed so as to equalize for parts the numbers of the recognition objects with the characteristic values within each part. Table 2 contains the discretization thresholds and values of $P$ that have been obtained for the characteristics listed above.

The characteristics for that $P<20 \%$ have been excluded from the further analysis. Exception has been made for $A_{\text {min }}$ to leave characteristic that reflects anomalies of geomagnetic field. Such characteristics showed their usefulness in solving the similar problem for the Caucasian region [Soloviev et al., 2016. Thus the following 9 characteristics are left: $H_{\max }, H_{\min }, \Delta H, \mathrm{~g} H, M o r, B_{\max }, B_{\min }, \Delta B$, and $A_{\min }$. The discretization has been made with two parts for $\Delta B$ and with three parts for other characteristics.

After the discretization the characteristic values are converted into components of binary vectors as shown in Table 3. After this conversion a vector with 18 binary components corresponds to each object of recognition.

\section{Application of the Pattern Recognition Algorithm}

The CORA-3 algorithm is applied to 97 vectors with binary components corresponding to the objects of recognition to classify them into classes $\mathbf{D}$ and $\mathbf{N}$. The decisive rule for the classification is composed of the voting threshold $\Delta$ and two sets of characteristic traits: the characteristic traits of class $\mathbf{D}$ (or $\mathbf{D}$-traits) and the characteristic traits of class $\mathbf{N}$ (or $\mathbf{N}$-traits). The recognition object is put into class $\mathbf{D}$ if the difference in the number of the $\mathbf{D}$-traits and $\mathbf{N}$-traits possessed by it does not less than $\Delta$. If this difference is less than $\Delta$ then the object is put into class $\mathbf{N}$.

The trait is described by six numbers: three integer numbers $i, j, k(1 \leq i \leq j \leq k \leq L$ where $L$ is the length of the binary vector corresponding to the object ( $L=18$ in our case) and three binary numbers $\delta_{1}, \delta_{2}, \delta_{3}$ that are either 0 or 1 . The recognition object that is the binary vector $\left(\omega_{1}, \omega_{2}\right.$, $\left.\ldots, \omega_{L}\right)$ has the trait if $\omega_{i}=\delta_{1}, \omega_{j}=\delta_{2}$, and $\omega_{k}=$ $\delta_{3}$. The trait is the $\mathbf{D}$-trait if the number of the objects from the training set $\mathbf{D}_{0}$ that have this trait is not less than the threshold $k_{1}$ and the number of the objects from the training set $\mathbf{N}_{0}$ that have this trait does not exceed the threshold $\bar{k}_{1}$. Corre- spondingly, the trait is the $\mathbf{N}$-trait if the number of the objects from the training set $\mathbf{N}_{0}$ that have this trait is not less than the threshold $k_{2}$ and the number of the objects from the training set $\mathbf{D}_{0}$ that have this trait does not exceed the threshold $\bar{k}_{2}$. The thresholds $k_{1}, \bar{k}_{1}, k_{2}$, and $\bar{k}_{2}$ are the parameters of the algorithm and their values should be specified during its application. The subordination and equivalence relationships between the characteristic traits of classes $\mathbf{D}$ and $\mathbf{N}$ are introduced. The characteristic trait $A$ is called as subordinate to another characteristic trait $B$ of the same class if all the objects of the training set of this class that have the trait $A$ also have the trait $B$ and if at least one object of the training set that has the trait $B$ does not have the trait $A$. Two characteristic traits are equivalent if they are possessed by the same objects of the corresponding training set. When forming the sets of the $\mathbf{D}$ - and $\mathbf{N}$-traits that compose the decisive rule for the classification, the algorithm excludes from the lists of characteristic traits those that are subordinate to any other characteristic trait and selects and only one trait from the group of the equivalent traits.

In our study the CORA-3 algorithm was applied with the following values of its parameters: $k_{1}=3, \bar{k}_{1}=1, k_{2}=15, \bar{k}_{2}=0$, and $\Delta=1$. Ten $\mathbf{D}$-traits and nine $\mathbf{N}$-traits have been selected by the algorithm. They are given in Table 4 in the form of inequalities on the values of the characteristics in accordance with the interpretation of the binary vector components (Table 3) and the discretization thresholds (Table 2).

The classification of the objects is reported in Table 5 where the voting (the numbers of $\mathbf{D}$-traits $n_{\mathrm{D}}$ and $\mathbf{N}$-traits $n_{\mathrm{N}}$ that the objects have) is given and objects that are put in class $\mathbf{D}$ are marked by "+". These nodes are also shown in Figure 2, Of 97 objects, $33(34 \%)$ and $64(66 \%)$ are classified $\mathbf{D}$ and $\mathbf{N}$, respectively. Class $\mathbf{D}$ is formed by 16 objects originally in $\mathbf{D}_{0}, 3$ originally in $\mathbf{N}_{0}$, and 14 not belonging to the training set. Nodes of class $\mathbf{D}$ are shown by circles in Figure 2 .

\section{Reliability Evaluation of the Result Obtained}

A set of control tests is usually executed to evaluate indirectly the reliability of the determination of earthquake-prone areas by pattern recognition 
Table 2. Discretization Thresholds and Values of $P$

\begin{tabular}{|l|c|c|c|c|}
\hline \multirow{2}{*}{ Characteristic } & \multicolumn{2}{|c|}{ Discretization into 2 parts } & \multicolumn{2}{c|}{ Discretization into 3 parts } \\
\cline { 2 - 5 } & Threshold & $P, \%$ & Thresholds & $P, \%$ \\
\hline$H_{\max }, \mathrm{m}$ & 2082 & 13 & $1740 ; 2372$ & 20 \\
\hline$H_{\min }, \mathrm{m}$ & 684 & 26 & $509 ; 916$ & 31 \\
\hline$\Delta H, \mathrm{~m}$ & 1298 & 9 & $1099 ; 1496$ & 22 \\
\hline$l, \mathrm{~m}$ & 37990 & 9 & $31700 ; 42790$ & 18 \\
\hline $\mathrm{g} H$ & 0.03887 & 15 & $0.02772 ; 0.05143$ & 29 \\
\hline$Q, \%$ & 19 & 7 & $10 ; 30$ & 18 \\
\hline$M o r$ & 2 & 36 & $2 ; 3$ & 36 \\
\hline$N_{l}$ & 2 & 7 & $2 ; 3$ & 17 \\
\hline$R_{h}$ & 1 & 2 & $1 ; 2$ & 3 \\
\hline$D_{\text {int }}, \mathrm{km}$ & 64 & 5 & $47 ; 84$ & 4 \\
\hline$D_{1}, \mathrm{~km}$ & 0 & 4 & $0 ; 70$ & 4 \\
\hline$D_{2}, \mathrm{~km}$ & 83 & 16 & $0 ; 107$ & 14 \\
\hline$N_{l c}$ & 3 & 4 & $2 ; 3$ & 12 \\
\hline$B_{\max }, \mathrm{mGal}$ & -144.17 & 36 & $-161.22 ;-118.80$ & 41 \\
\hline$B_{\min }, \mathrm{mGal}$ & -200.72 & 44 & $-225.84 ;-182.44$ & 57 \\
\hline$\Delta B, \mathrm{mGal}$ & 55.52 & 26 & $43.51 ; 66.49$ & 12 \\
\hline$A_{\max }, \mathrm{nT}$ & 117.97 & 10 & $83.29 ; 172.62$ & 3 \\
\hline$A_{\min }, \mathrm{nT}$ & -123.46 & 3 & $-169.54 ;-103.81$ & 14 \\
\hline$\Delta A, \mathrm{nT}$ & 269.11 & 3 & $200.27 ; 332.02$ & 8 \\
\hline
\end{tabular}

Table 3. Conversion of the Characteristic Values into Components of Binary Vectors

\begin{tabular}{|l|c|c|c|}
\hline \multirow{2}{*}{ Characteristics } & \multicolumn{3}{|c|}{ Characteristic values } \\
\cline { 2 - 4 } & "small" & "medium" & "large" \\
\hline$H_{\max }, H_{\min }, \Delta H, \mathrm{~g} H, B_{\max }, B_{\min }, A_{\min }$ & 11 & 01 & 00 \\
\hline$M o r$ & 100 & 010 & 001 \\
\hline$\Delta B$ & 1 & - & 0 \\
\hline
\end{tabular}

methods [Gelfand et al., 1976, Gorshkov et al., 2003a, 2004. Gorshkov, 2010: Gvishiani et al., 1988. Describing the tests that have been run in our case we call the classification result given in Table 5 as the main result.

In the first test, the recognition has been performed with a modified training set $\left(\mathbf{D}_{0}\right.$ and $\left.\mathbf{N}_{0}\right)$. The subset $\mathbf{D}_{0}$ has been formed by the objects from the set $\mathbf{X}$ which were recognized $\mathbf{D}$ in the main variant. Correspondingly, subset $\mathbf{N}_{0}$ has been formed by the objects from the set $\mathbf{X}$ which were classified $\mathbf{N}$ in the main variant. Classification of 6 objects ( $6 \%$ of the total number of objects) is changed in the test compared with the main variant. These are the objects with the following numbers: 44,45 , $73,78,83$, and 91 .
In the second test the subsets $\mathbf{D}_{0}$ and $\mathbf{N}_{0}$ include all objects recognized in the main variant as $\mathbf{D}$ and $\mathbf{N}$, respectively. Classification of 3 objects (3\% of the total number of objects) is changed in this test compared with the main variant. These are the objects with the following numbers: 72,73 , and 91 .

The next test has been done to check dependence of the recognition result on specific traits that are selected from the equivalent trait groups. In this test the recognition object is put into class $\mathbf{D}$ if for it $u_{\mathrm{D}}-u_{\mathrm{N}} \geq \Delta$, otherwise the object is put into class N. Here

$$
u_{\mathrm{D}}=\sum_{i=1}^{n_{\mathrm{D}}} m_{\mathrm{D}}^{i} / n_{\mathrm{D}}^{i}, \quad u_{\mathrm{N}}=\sum_{i=1}^{n_{\mathrm{N}}} m_{\mathrm{N}}^{i} / n_{\mathrm{N}}^{i},
$$

$n_{\mathrm{D}}$ and $n_{\mathrm{N}}$ are the numbers of characteristic 


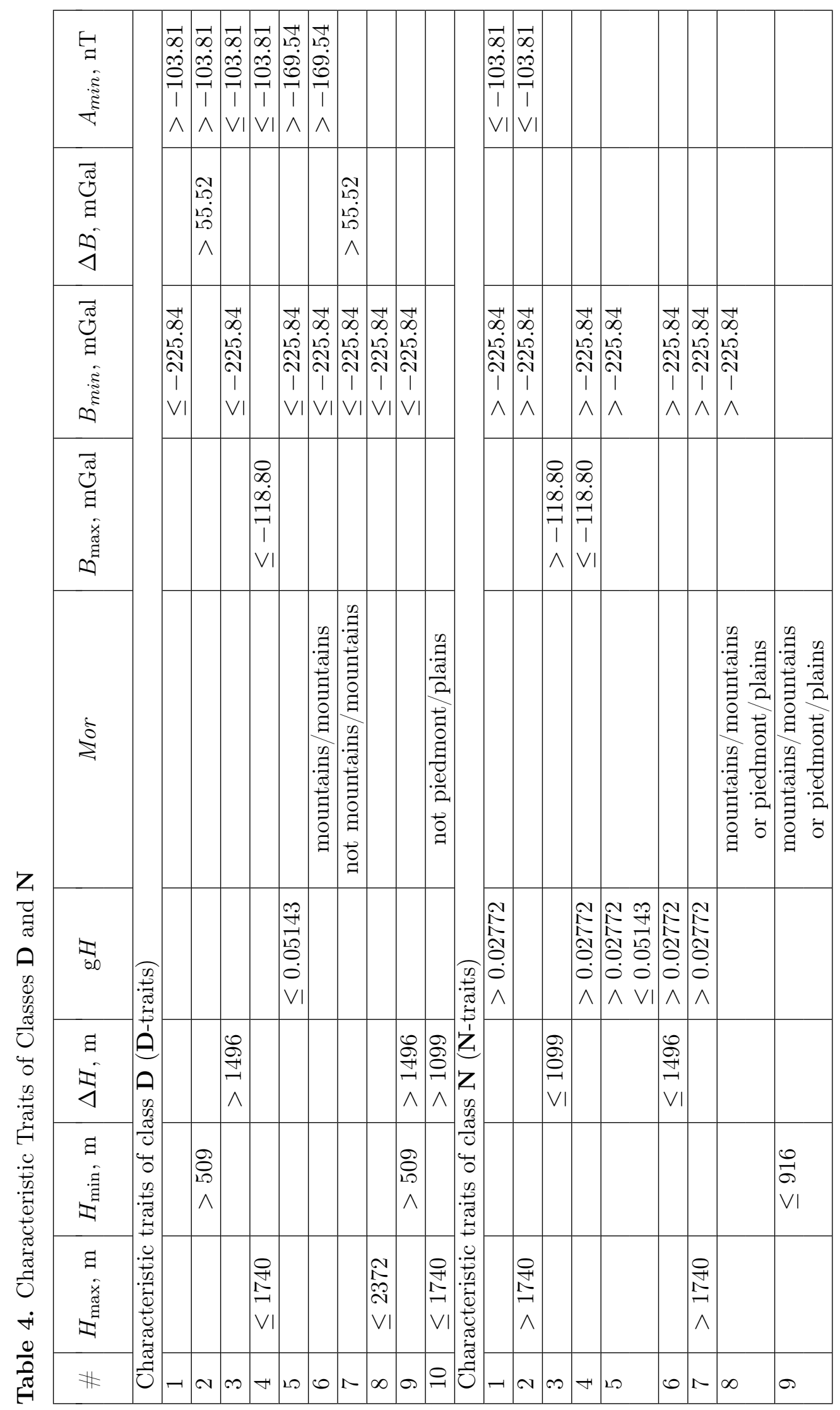




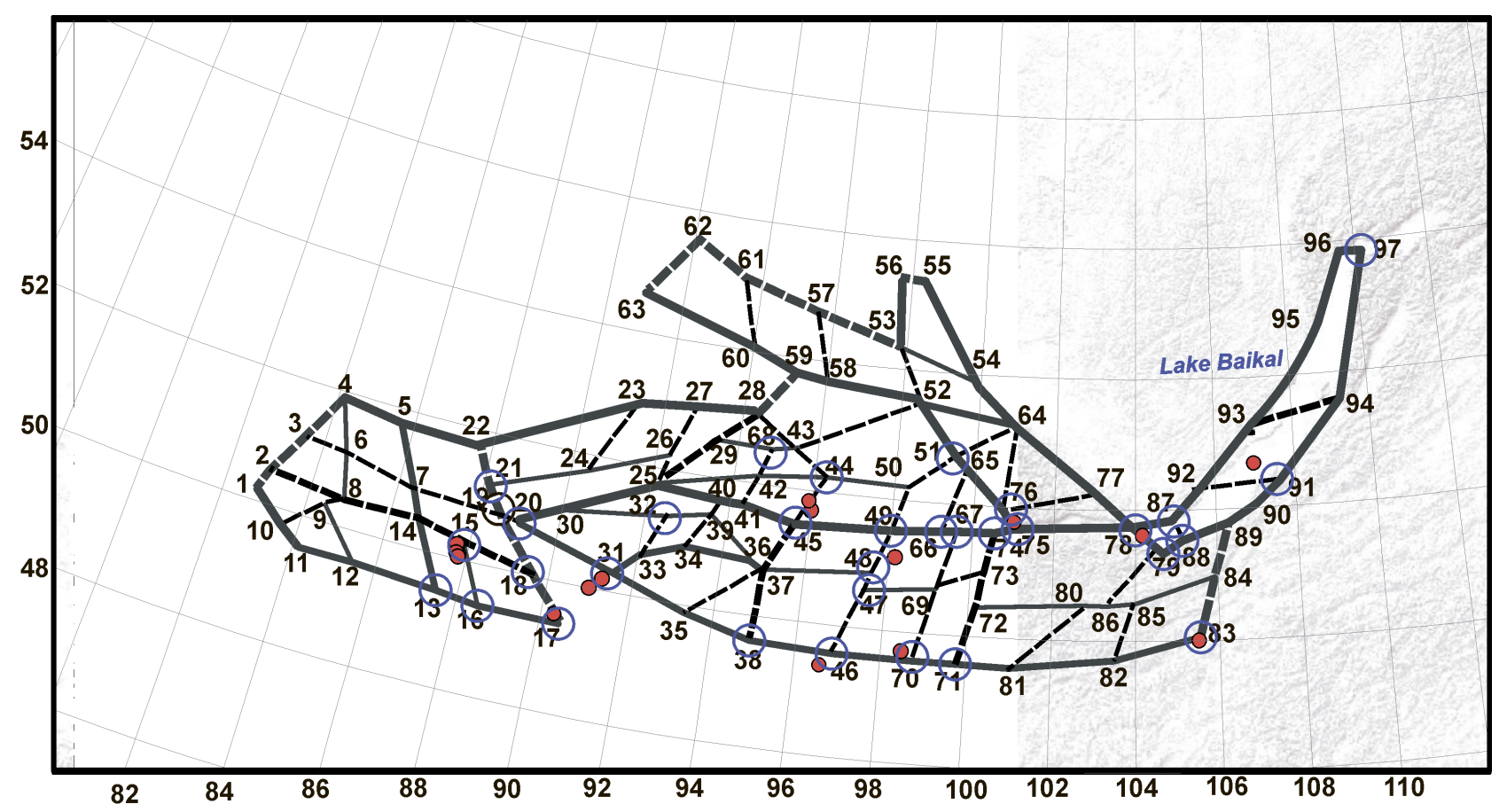

Figure 2. Morphostructural map of the Altai-Sayan-Baikal region. Continuous lines mark the longitudinal lineaments, dashed lines depict the transverse lineaments. Bold lines show the lineaments of the 1st rank, middle lines mark the lineaments of the 2nd rank, hairlines depict the lineaments of the 3rd rank. Red dots depict epicentres of earthquakes M6+. A - Altai, WS - Western Sayan, EW - Eastern Sayan, B - Baikal, T

- Tuva Mountains. Roman figures indicate numbers of nodes.

D- and N-traits selected by the CORA-3 algorithm (10 and 9 in the main variant, Table 4 ), $n_{\mathrm{D}}^{i}$ and $n_{\mathrm{N}}^{i}$ are the numbers of characteristic traits in the groups of traits that are equivalent to the $\mathbf{D}$-trait numbered $i$ in Table 4 and to the $\mathbf{N}$-trait numbered $i$ respectively, $m_{\mathrm{D}}^{i}$ and $m_{\mathrm{N}}^{i}$ are the numbers of characteristic traits that the object has from the relevant groups of equivalent traits. Classification of only one object numbered 21 is changed in this test compared with the main variant.

The results of the tests described above are indirect arguments favoring the validity of the main variant; the changes, with respect to the main variants, during these tests do not exceed 6\%. Such insignificant changes with respect to the main variant are in agreement with the empirical stability criteria developed by Gvishiani et al., 1988 .

One more test is devoted to estimate contributions of the individual characteristics listed in Table 2 to the result obtained. For this purpose each of the nine characteristics used in the main variant is eliminated from consideration one at a time and classification is made by means of the CORA-3 al- gorithm. The results of this test are presented in Table 6.

One can see that the maximum number of objects classification of which is changed in this test is 14 , that is less than $15 \%$ of the total number of objects. It means that the recognition result is rather stable when one characteristic is eliminated. Note that classification is changed for the maximal number of objects when characteristic $B_{\min }$ is eliminated. This characteristic has the largest value of $P$ (Table 2), which is regarded as a measure of the characteristic informativity.

\section{Discussion and Conclusion}

Most of the recognized $\mathbf{D}$ nodes are located on the lineaments of the highest, first and second, ranks, which divide the largest morphostructures.

In Altai, D nodes are recognized in its southeastern part. Nodes 19, 20, and 21 are located on the border of Altai with the Western Sayan; nodes 
Table 5. Voting of Objects by $\mathbf{D}$ - and $\mathbf{N}$-traits

\begin{tabular}{|c|c|c|c|c|c|}
\hline \multirow[t]{2}{*}{ Object numbers } & Voting & \multirow[t]{2}{*}{ Object numbers } & Voting & \multirow[t]{2}{*}{ Object numbers } & Voting \\
\hline & $n_{\mathrm{D}}: n_{\mathrm{N}}$ & & $n_{\mathrm{D}}: n_{\mathrm{N}}$ & & $n_{\mathrm{D}}: n_{\mathrm{N}}$ \\
\hline \multicolumn{2}{|c|}{ Objects from $\mathbf{D}_{0}$} & 27 & $0: 5$ & 93 & $0: 1$ \\
\hline 15 & $3: 0+$ & 28 & $0: 6$ & 95 & $0: 1$ \\
\hline 17 & $3: 0+$ & 29 & $0: 8$ & \multicolumn{2}{|c|}{ Objects from $\mathrm{X}$} \\
\hline 31 & $4: 0+$ & 30 & $0: 4$ & 13 & $3: 0+$ \\
\hline 44 & $1: 0+$ & 35 & $0: 0$ & 14 & $0: 7$ \\
\hline 45 & $1: 0+$ & 36 & $0: 5$ & 16 & $1: 0+$ \\
\hline 46 & $1: 0+$ & 37 & $0: 6$ & 18 & $4: 0+$ \\
\hline 48 & $3: 0+$ & 40 & $0: 1$ & 19 & $4: 1+$ \\
\hline 49 & $2: 0+$ & 41 & $0: 3$ & 20 & $4: 0+$ \\
\hline 70 & $2: 0+$ & 42 & $0: 6$ & 25 & $0: 6$ \\
\hline 74 & $3: 0+$ & 51 & $2: 0+$ & 26 & $1: 4$ \\
\hline 75 & $4: 0+$ & 52 & $0: 8$ & 32 & $5: 0+$ \\
\hline 76 & $1: 0+$ & 53 & $0: 1$ & 33 & $0: 0$ \\
\hline 78 & $1: 0+$ & 54 & $0: 3$ & 34 & $0: 5$ \\
\hline 79 & $5: 0+$ & 55 & $0: 3$ & 38 & $1: 0+$ \\
\hline 83 & $1: 0+$ & 56 & $0: 3$ & 39 & $0: 3$ \\
\hline 91 & $1: 0+$ & 58 & $0: 7$ & 43 & $1: 4$ \\
\hline \multicolumn{2}{|c|}{ Objects from $\mathbf{N}_{0}$} & 59 & $0: 7$ & 47 & $5: 0+$ \\
\hline 1 & $0: 3$ & 60 & $0: 2$ & 50 & $0: 0$ \\
\hline 2 & $0: 3$ & 61 & $0: 3$ & 57 & $0: 5$ \\
\hline 3 & $0: 6$ & 62 & $0: 3$ & 65 & $0: 0$ \\
\hline 4 & $0: 3$ & 63 & $0: 3$ & 66 & $3: 0+$ \\
\hline 5 & $0: 5$ & 64 & $0: 1$ & 67 & $2: 0+$ \\
\hline 6 & $1: 3$ & 69 & $0: 0$ & 68 & $2: 1+$ \\
\hline 7 & $0: 2$ & 71 & $1: 0+$ & 77 & $0: 1$ \\
\hline 8 & $0: 1$ & 72 & $0: 0$ & 87 & $4: 0+$ \\
\hline 9 & $0: 7$ & 73 & $0: 0$ & 88 & $3: 0+$ \\
\hline 10 & $0: 4$ & 80 & $0: 2$ & 89 & $1: 2$ \\
\hline 11 & $0: 6$ & 81 & $0: 7$ & 90 & $0: 1$ \\
\hline 12 & $0: 3$ & 82 & $0: 6$ & 92 & $1: 2$ \\
\hline 21 & $2: 1+$ & 84 & $0: 1$ & 94 & $2: 2$ \\
\hline 22 & $0: 6$ & 85 & $0: 3$ & 96 & $0: 3$ \\
\hline 23 & $0: 4$ & 86 & $0: 2$ & 97 & $2: 0+$ \\
\hline 24 & $0: 7$ & & & & \\
\hline
\end{tabular}

Table 6. Numbers of Objects Classification of Which is Changed Compared with the Main Variant when Characteristics are Eliminated from Consideration

\begin{tabular}{|l|l|l|l|l|l|l|l|l|l|}
\hline \multirow{2}{*}{$\begin{array}{l}\text { Classification } \\
\text { change }\end{array}$} & \multicolumn{6}{|l|}{ Eliminated characteristic } \\
\cline { 2 - 9 } & $H_{\max }$ & $H_{\min }$ & $\Delta H$ & $\mathrm{~g} H$ & Mor & $B_{\max }$ & $B_{\min }$ & $\Delta B$ & $A_{\min }$ \\
\hline $\mathbf{D} \rightarrow \mathbf{N}$ & 44,68, & 45 & 49,51 & 16,71, & & 44,83 & 16,19, & 45,71 & 19,21, \\
& 78,83, & & & 76,78, & & & 21,32 & & 67 \\
& 91 & & & 91 & & & 46,67 & \\
& & & & & & & 68,76 & \\
& & & & & & & 88,97 & & \\
\hline $\mathbf{N} \rightarrow \mathbf{D}$ & 72 & & 77,90 & & 6,43, & & 12,33, & & 8,33, \\
& & & & & 89,92, & & 89,94 & & 35,40, \\
& & & & & 94 & & & & 89 \\
\hline
\end{tabular}


17 and 18 sit on the border with the Great Lakes basin, and nodes 13 and 16 are at the boundary with Mongolian Altai.

High-seismic nodes 45, 49, 66, 67, 74, 75 and 78, located on the lineament of the first rank, which separates the Western and Eastern Sayan Mountains from the Tuva Mountains and the intermountain depressions between them. This lineament is consistent with the Bolnisi and Tunkin faults. Seismogenic nodes 38, 46, 70, 71 and 83 are situated on the southern border of the Tuva Mountains that corresponds to the Khangai fault. In Baikal Lake, D nodes, 78, 79, 87, 88 and 91, are concentrated on the borders of the South Baikal Basin.

Most nodes situated in the Western and Northwestern Altai, in the inner areas of the Western Sayan, in the almost entire Eastern Sayan, as well as at the western boundary of the Baikal Lake have been assigned to $\mathbf{N}$.

D nodes, where events with $M \geq 6.0$ have not yet been documented, spread over the region as follows. D nodes 18-21 sit on the eastern boundary of Gorny Altai, and D nodes 13 and 16 are located on the limit between Gorny and Mongolian Altai. The high seismic potential of the western and southern boundaries of Gorny Altai is confirmed by paleoseismic studies [Deev et al., 2012, 2013, Rogozhin et al., 2002.

Nodes 44, 51, 68 are located in the inner areas of the eastern part of the Western Sayan where no strong events have been observed so far. However, near node 44, paleoseismic features associated with an earthquake in the magnitude range of 6.9-7.4 were found by Arzhannikov, 2000, 2003. At node 68, the paleoseismic features likely caused by M6.5 tectonic earthquake was mapped by Arzhannikov, 2000. Nodes 38 and 71 are located on the southern border of the Tuva Mountains in the Khangai fault zone. Arzhannikova and Arzhannikov, 1999, Arzhannikov and Arzhannikova, 2011 found the paleoseismic features a little to the north of node 38 suggesting an earthquake of magnitude 7.5-7.8. Several closely located paleoseismic features were found by Kochetkov et al., 1993 in the area of node 71. They could have been generated by earthquakes with $M=6.8-7.3$. Nodes 87 and 88 are located at the southern end of the Baikal depression, which is characterized by high rate of seismic activity. Sankov et al., 2014 suggest the possible occurrence of an earthquake with $M=7.5-7.6$ in the southern part of Baikal Lake. D node 97 is located in the northern part of Lake Baikal, where it joins the seismically active zone of the Upper Angara rift system.

The characteristic features of classes $\mathbf{D}$ and $\mathbf{N}$ selected by the CORA-3 algorithm presented by numbered lines in Table 4 . Their assemblage point out that seismogenic nodes are characterized by the increased contrast of the neotectonic movements and an increased tectonic fragmentation of seismogenic nodes.

The results of the study reveal a high seismic potential of the studied region and provide locations of potential sources of earthquakes with $M \geq$ 6.0. The information on the potential earthquake sources is important for calculating seismic hazard assessments using both probabilistic and deterministic methods. In particular, the data on seismogenic nodes for $M \geq 6.0$, which were recognized in the Italian region [Gorshkov et al., 2002, 2004, were then used in the calculations of seismic hazard using the NDSHA method [Peresan et al., 2011. 2015.

Locations of seismogenic nodes can be helpful in the selecting a perspective target sites for paleoseismic research.

Acknowledgments. The reported study was funded by RFBR, project number 20-05-00171.

\section{References}

Alekseevskaya, E. I., A. M. Gabrielov, A. D. Gvishiani, et al. (1977), Formal morphostructural zoning of mountain territories, J. Geophys., 43, 227-233.

Arzhannikova, A. V., S. G. Arzhannikov (1999), Seismotectonic deformations in the western part of the Tunka Goltsov and modern exogeodynamics, Geology and Geophysics, 40, 231-234.

Arzhannikov, S. G. (2000), Paleoseismic features in the zone of influence of the Ottugino-Azas fault (Eastern Tuva), Geology and Geophysics, 41, 1499-1509.

Arzhannikov, S. G. (2003), Main active faults, kinematics and strong paleoearthquakes in the eastern part of the Altai-Sayan mountainous region, Stressstrain state and seismicity of the lithosphere. Proceedings of the All-Russian meeting, Irkutsk, IZK SB RAS, August 26-29, 2003, p. 241-248, Publishing house of SB RAS, Novosibirsk, Russia.

Arzhannikov, S. G., A. V. Arzhannikova (2011), The Late Quaternary geodynamics of the Hyargas Nuur basin and bordering scarps (Western Mongolia), Russian Geology and Geophysics, 52, No. 2, 220-229, Crossref 
Bhatia, S. C., T. R. K. Chetty, M. Filimonov, et al. (1992), Identification of potential areas for the occurrence of strong earthquakes in Himalayan arc region, Proc. Indian Acad. Sci. (Earth Planet. Sci.), 101, No. 4, 369-385.

Buslov, M. M., D. A. Kokh, J. De Grave (2008), Mesozoic-Cenozoic tectonics and geodynamics of Altai, Tien Shan and Northern Kazakhstan, from apatite fission-track date, Russian Geology and Geophysics, 49, No. 9, 648-654, Crossref

Buslov, M. M., A. V. Travin, V. G. Kulikova (2013), Tectonics and geodynamics of Gorny Altai and adjacent structures of the Altai-Sayan folded area, Russian Geology and Geophysics, 54, No. 10, 12501271, Crossref

Caputo, M., V. Keilis-Borok, E. Oficerova, et al. (1980), Pattern recognition of earthquake-prone areas in Italy, Phys. Earth Planet Int., 21, 305320.

Chunga, K., A. Michetti, A. Gorshkov, et al. (2010), Identificacion de nudos sismogenicos capaces de generar potenciales terremotos de $M>6$ y $M>6.5$ en la Región costera y cadenas montanosas de los Andes Septentrionales del Ecuador, Revista Tecnologica ESPOL - RTE, 23, 61-89.

Cisternas, A., P. Godefroy, A. Gvishiani, et al. (1985), A dual approach to recognition of earthquake prone areas in the western Alps, Annales Geophysicae, 3, 249-270.

Deev, E. V., I. D. Zolnikov, S. V. Goltsova, et al. (2012), Neotectonics and paleoseismicity of the Lower Katun valley (Gorny Altai), Russian Geology and Geophysics, 53, No. 9, 883-894, Crossref

Deev, E. V., S. V. Goltsova, A. A. Emanov, et al. (2013), Traces of paleoearthquakes in the Quaternary deposits of intermontane basins in central Gorny Altai, Russian Geology and Geophysics, 54, No. 3, 312-323, Crossref

Dergunov, L. (1989), Caledonides of the Central Asia, 191 pp. Nauka, Moscow, Russia.

Dobretsov, N. L., N. A. Berzin, M. M. Buslov, et al. (1995), General problems of the evolution of the Altai region and the relationship between the structure of the basement and the development of the neotectonic structure, Geology and Geophysics, 36, No. 10, $5-19$.

Dobretsov, N. L., A. N. Vasilevsky, N. N. Nevedrova, et al. (2016), Cenozoic history of topography in Southeastern Gorny Altai: Thermochronology and resistivity and gravity records, Russian Geology and Geophysics, 57, No. 11, 1525-1534, Crossref

Dyment, J., V. Lesur, M. Hamoudi (2015), World Digital Magnetic Anomaly Map version 2.0., Stressstrain state and seismicity of the lithosphere. Proceedings of the All-Russian meeting, Irkutsk, IZK SB RAS, August 26-29, 2003, WDMAM, France. (http://www.wdmam.org)

Gelfand, I. M., Sh. A. Guberman, M. L. Izvekova, etal. (1972), Criteria of high seismicity determined by pattern recognition, Tectonophysics, 13 415-422.
Gelfand, I. M., Sh. A. Guberman, V. I. Keilis-Borok, et al. (1976), Pattern recognition applied to earthquake epicenters in California, Phys. Earth Planetary Interior, 11, 227-283.

Gorshkov, A. I., I. V. Kuznetsov, A. A. Soloviev, et al. (2000), Identification of future earthquake sources in the Carpatho-Balkan orogenic belt using morphostuctural criteria, Pure and Applied Geophysics, 157, No. 1-2, 79-95, Crossref

Gorshkov, A. I., G. F. Panza, A. A. Soloviev, et al. (2002), Morphostructural zonation and preliminary recognition of seismogenic nodes around the Adria margin in peninsular Italy and Sicily, Journal of Seismology and Earthquake Engineering, 4, No. 1, $1-24$.

Gorshkov, A., V. Kossobokov, A. Soloviev (2003a), Recognition of Earthquake-Prone Areas, Nonlinear Dynamics of the Lithosphere and Earthquake Prediction p. 239-310, Springer, Berlin, Heidelberg. Crossref

Gorshkov, A. I., G. F. Panza, A. A. Soloviev, et al. (2003b), Recognition of the strong earthquake-prone areas $(M \geq 6.0)$ within the mountain belts of CentralEurope, Revue Roumaine de Geophysique, 47, 3041.

Gorshkov, A. I., G. F. Panza, A. A. Soloviev, et al. (2004), Identification of seismogenic nodes in the Alps and Dinarides, Bolletino della Societa Geologica Italiana, 123, 3-18.

Gorshkov, A. I., M. Mokhtari, E. P. Piotrovskaya (2009a), The Alborz region: Identification of seismogenic nodes with morphostructural zoning and pattern recognition, J. Seismolog. Earthq. Engineering, $11,1-15$.

Gorshkov, A. I., G. F. Panza, A. A. Soloviev, et al. (2009b), Delineation of the geometry of nodes in the Alps-Dinarides hinge zone and recognition of seismogenic nodes $(M \geq 6)$, Terra Nova, 21, 257264, Crossref

Gorshkov, A. I., A. A. Soloviev, M. J. Jiménez, et al. (2010), Recognition of earthquake-prone areas $(M \geq 5.0)$ in the Iberian Peninsula, Rendiconti Lincei, 21, 131-162, Crossref

Gorshkov, A. I. (2010), Recognition of the StrongEarthquake Prone Areas in the Alpine-Himalaya Belt, Computational Seismology, 40, 472. (in Russian)

Gorshkov, A., I. A. Parvez, O. Novikova, et al. (2012), Recognition of earthquake-prone areas in the Himalaya: validity of the results, International Journal of Geophysics, 2012, 5, Crossref

Gorshkov, A., A. Soloviev, Yu. Zharkikh (2017), A Morphostructural Zoning of the Mountainous Crimea and the Possible Locations of Future Earthquakes, J. Volcanolog. Seismolog., 11, 407-412, Crossref

Gorshkov, A., O. Novikova (2018), Estimating the validity of the recognition results of earthquake-prone areas using the ArcMap, Acta Geophysica, 66. Is. 5, 843-853, Crossref

Gorshkov, A., Y. Gaudemer (2019), Seismogenic 
nodes defined with pattern recognition in the French Massif Central, J. Iberian Geol., 45, 63-72, Crossref

Gorshkov, A. I., H. M. Hassan, O. V. Novikova (2019), Seismogenic nodes $(M \geq 5.0)$ in Northeast Egypt and implications for seismic hazard assessment, Pure Appl. Geophys., 176, 593-610, Crossref

Gorshkov, A. I., O. V. Novikova, I. Gaudemer (2020), Strong $(M \geq 7.0)$ earthquake-prone areas in Hellenides, Greece, Izv., Phys. Solid Earth, 56, 45-52, Crossref

Gvishiani, A., A. Soloviev (1981), Association of the epicenters of strong earthquakes with the intersections of morphostructural lineaments in South America, Computational Seismology, 13, 46-50.

Gvishiani, A. D., A. A. Soloviev (1984), Recognition of places on the Pacific coast of the South America where strong earthquakes may occur, Earthq. Predict. Res., 2, 237-243.

Gvishiani, A., A. Gorshkov, V. Kossobokov, et al. (1987), Identification of seismically dangerous zones in the Pyrenees, Annales Geophysicae, 6, 681-690.

Gvishiani, A. D., A. I. Gorshkov, E. Ya. Rantsman, et al. (1988), Recognition of Earthquake-Prone Areas in the Regions of Moderate Seismicity, 240 pp. Nauka, Moscow, Russia.

Gvishiani, A. D., A. A. Soloviev, B. A. Dzeboev (2020), Problem of Recognition of Strong-Earthquake-Prone Areas: a State-of-the-Art Review, Izv., Phys. Solid Earth, 56, 1-23, Crossref

Imaev, V. S., L. P. Imaeva, O. P. Smekalin, et al. (2006), Architectonics of the Altai region and its potential seismic hazard, Active geological and geophysical processes in the lithosphere. Methods, means and results of the study. Materials of the XII International Conference, Voronezh, September 18-23, 2006, p. 220-223, Voronezh State University Publishing House, Voronezh, Russia.

Kochetkov, V. M., S. D. Khilko, A. V. Chipizubov, et al. (1993), Strong Earthquakes, Seismotectonics and Seismicity of the Khubsugul region p. 70-79, Nauka, Novosibirsk, Russia. (in Russian)

Kondorskaya, N. V., P. N. Shebalin (1977), A New Catalog of Strong Earthquakes in the USSR from Ancient Times to 1975, 536 pp. Nauka, Moscow, Russia. (in Russian)

Kondorskaya, N., P. Shebalin, Y. Khrometskaya, et al. (1982), New Catalog of the Strong Earthquakes of the USSR from Ancient Times through 197r, 608 pp. WDC A for Solid Earth Geophysics, NOAA, National Geophysical Data Center, Boulder, Colorado, USA.

Kondorskaya, N. V., I. V. Gorbunova, O. V. Kireev, et al. (1993), On compiling a unified catalog of strong earthquakes in Northern Eurasia using instrumental data, Seismicity and Seismic Zoning of Northern Eurasia p. 70-79, Minnauki Rossii, Moscow, Russia. (in Russian)

Kossobokov, V. G. (1983), Recognition of the sites of strong earthquakes in East Central Asia and Anatolia by Hamming's method, Computational Seismology, 14, 78-82.

Lukina, N. V. (1996), Altai active faults and seismicity, Geology and Geophysics, 37, 71-74.

Lunina, O. V., A. S. Gladkov, A. A. Gladkov (2012), Systematization of Active Faults for the Assessment of the Seismic Hazard, Russ. J. of Pac. Geol., 6, 42-51, Crossref

Molnar, P., P. Tapponnier (1975), Cenozoic tectonics of Asia: Effect of a continental collision, Science, 189, No. 4201, 419-425, Crossref

Novikov, I. S. (2004), Morphotectonics of Altai, 313 pp. Publishing House of SB RAS, Branch "Geo", Novosibirsk, Russia. (in Russian)

Novikova, O., A. Gorshkov (2013), Recognition of earthquake prone areas $(M \geq 6.0)$ in the Kopet Dagh region using the GIS technology, J. Seismolog. Earthq. Engineering, 15, 101-109.

Novikova, O., A. Gorshkov (2016), Seismogenic nodes defined by pattern recognition in the central part of the Alpine-Himalayan belt, Bull. Geolog. Soc. Greece, 50, 1426-1432, Crossref

Novikova, O. V., A. I. Gorshkov (2018), High seismicity intersections of morphostructural lineaments: the Black-Sea-Caspian region, J. Volcanolog. Seismolog, 12, 379-387, Crossref

Peresan, A., E. Zuccolo, F. Vaccari, et al. (2011), Neo-deterministic seismic hazard and pattern recognition techniques: Time-dependent scenarios for NorthEastern Italy, Pure Appl. Geophys., 168, 583-607, Crossref

Peresan, A., A. Gorshkov, A. Soloviev, et al. (2015), The contribution of pattern recognition of seismic and morphostructural data to seismic hazard assessment, Bollettino di Geofisica Teorica ed Applicata, 56, 295-328, Crossref

Rantsman, E. Ya. (1979), Locations of the Earthquakes and Morphostructure of Mountain Regions, 171 pp. Nauka, Moscow, Russia. (in Russian)

Rogozhin, E. A., S. G. Platonova (2002), Focal Zones of Strong Earthquakes in Mountainous Altai in the Holocene, 130 pp. UIPE RAS, Moscow, Russia. (in Russian)

Sabaka, T. J., N. Olsen, M. E. Purucker (2004), Extending comprehensive models of the Earth's magnetic field with Ørsted and CHAMP data, Geophys. J. Int., 159, 521-547, Crossref

Sankov, V., A. Lukhnev, A. Miroshnitchenko, et al. (2014), Contemporary horizontal movements and seismicity of the South Baikal Basin (Baikal Rift System), Izvestiya, Physics of the Solid Earth, 50, 785794, Crossref

Sherman, S. I., M. Jin, E. A. Gorbunova (2015), Recent strong earthquakes in Central Asia: Regular tectonophysical features of locations in the structure and geodynamics of the lithosphere. Part1. Main geodynamic factors predetermining locations of strong 
earthquakes in the structure of the lithosphere in Central Asia, Geodynamics and Tectonophysics, 6, 409436, (in Russian) Crossref

Soloviev, A. A., O. V. Novikova, A. I. Gorshkov, et al. (2013), Recognition of potential sources of strong earthquakes in the Caucasus region using GIS technologies, Doklady Earth Sciences, 450, 658-660, Crossref

Soloviev, A. A., A. D. Gvishiani, A. I. Gorshkov, et al. (2014), Recognition of earthquake-prone areas: Methodology and analysis of the results, Izv., Phys. Solid Earth, 50, 151-168, Crossref

Soloviev, Al. A., A. I. Gorshkov, An. A. Soloviev (2016), Application of the data on the lithospheric magnetic anomalies in the problem of recognizing the earthquake prone areas, Izv., Phys. Solid Earth, 52, 803-809, Crossref
Trifonov, V. G., O. V. Soboleva, R. V. Trifonov, et al. (1979), Modern Geodynamics of the AlpineHimalayan Collision Belt, 224 pp. Geos, Moscow, Russia. (in Russian)

Wells, D. L., K. J. Coppersmith (1994), New empirical relationships among magnitude, rupture length, rupture width, and surface displacement, Bulletin of the Seismological Society of America, 84, 974-1002.

Corresponding author:

A. A. Soloviev, Institute of Earthquake Prediction Theory and Mathematical Geophysics, Russian Academy of Sciences, 84/32 Profsoyuznaya Str., 117997, Moscow, Russia.(soloviev@mitp.ru) 